\title{
A ASCENSÃO DO JUDICIÁRIO BRASILEIRO: UMA ANÁLISE SOBRE SEU POSICIONAMENTO NO CENÁRIO POLÍTICO HISTÓRICO
}

\author{
Diego Ferreira Pimentel¹; Carlos Eduardo Behrmann Rátis Martins². \\ 1. Diego Ferreira Pimentel, Bolsista do PEVIC, Direito, Universidade Estadual de Feira de Santana, e-mail: \\ diegopimentel.pj@gmail.com \\ 2. Carlos Eduardo Behrmann Rátis Martins, Departamento de Ciências Sociais Aplicada, Universidade Estadual de Feira de \\ Santana, e-mail: carlosratis@uol.com.br
}

PALAVRAS-CHAVE: História constitucional; Judiciário brasileiro; Expansão judiciária; Supremo Tribunal Federal.

\section{INTRODUÇÃO}

O debate sobre o crescimento do poder judiciário no Brasil, especialmente pela figura do Supremo Tribunal Federal, é um tema que tem dominado parte dos juristas e cientistas políticos que analisam o fenômeno do ativismo judicial. Ocorre que os estudos realizados, em sua maioria, se distanciam do quesito histórico e criam a falsa compreensão de que a ascensão desse poder (que, por longo período, foi alheio ao processo político) se dá apenas por causas recentes.

Sob essa perspectiva, o trabalho se concentrou em analisar o desenvolvimento do Estado constitucional com as revoluções burguesas, a qual possibilitou a visão de como esse modelo estruturou a existência de poderes harmônicos e independentes. Apontou-se, posteriormente, como o surgimento do neoconstitucionalismo, após a segunda guerra mundial, alterou a atuação dos juízes levando ao seu "endeusamento".

Feita essa exposição, realizou-se na segunda parte uma análise histórica do poder judiciário brasileiro, ao longo das Constituições que vigoraram e ora vigora no país, no escopo de se responder quando esse processo teve seu início e quais foram os pressupostos jurídicos que alteraram o papel do magistrado sobre a atuação política na história do país. Concluiu-se, ao final, que o crescimento da atividade judiciária, que despontou o ativismo judicial visto na atualidade, teve início na década de 30 com a criação de ações que possibilitaram aos juízes analisarem o mérito dos atos políticos.

Propôs-se analisar, dessa forma, cada Constituição que vigorou no país aliando esse estudo a inserção da Lei Fundamental no contexto político do período em que esteve em vigor. Com isso, apontando-se o papel do juiz desde o período imperial e sua atuação restrita a matérias cíveis e penais aos demais períodos republicanos, como o início desse regime e a tentativa fracassada de se criar um novo modelo judicial, a Era Vargas e a ditadura civilmilitar que subtraíram o papel do magistrado, bem como o Brasil pós- 88 e a ascensão do neoconstitucionalismo, analisando e inter-relacionando os fatores ocorridos em cada período.

\section{MATERIAL E MÉTODOS OU METODOLOGIA (ou equivalente)}

O debate sobre o tema do desenvolvimento do judiciário no cenário constitucional brasileiro, sob o enfoque da evolução da interpenetração judicial no debate político, deu-se a partir de uma análise normativa e bibliográfica.

No primeiro momento, sob análise das considerações feitas por juristas que enfocaram seus estudos em ramificações do tema, analisamos como ocorreu o desenvolvimento do 
Estado Constitucional de Direito, trazendo-se a debate desde o surgimento do constitucionalismo moderno ao neoconstitucionalismo e a influência desse processo no papel de atuação do magistrado.

Na segunda parte, com a conclusão de que a história constitucional em sentido amplo revelava uma ampliação das prerrogativas de atuação do magistrado, partimos para a análise do caso específico brasileiro. Nessa linha, fez-se um levantamento bibliográfico dos autores que abordaram o tema, trazendo-lhes suas principais considerações e, ao mesmo tempo, confrontando-as de maneira crítica e relacionando-as com as normas que vigoraram em cada Carta.

\section{RESULTADOS E/OU DISCUSSÃO (ou Análise e discussão dos resultados)}

1. O desenvolvimento do constitucionalismo moderno e do neoconstitucionalismo possuem relação com a atuação do poder judiciário, na medida que o surgimento do primeiro rompeu com o absolutismo, estabelecendo a independência entre os poderes, ao passo que o segundo elevou o papel do magistrado na função interpretativa das normas;

2. No caso brasileiro, a Constituição Imperial brasileira de 1822 representou a hegemonia do poder monárquico, no qual - sem a separação de poderes e amplo controle do Império - não houve eminência do poder judiciário;

3. A Carta de 1891, a primeira do período republicano, consagrou a independência entre os poderes. Em que pese ter sido considerado "letra-morta", em face de sua falta de efetividade no plano prático, a Constituição inaugurou no Brasil o sistema de controle de constitucionalidade no plano formal, onde apesar da falta de atuação no judiciário no controle efetivo das normas, desenhou-se os primeiros na mudança de paradigma do judiciário que seriam concretizados nas Constituições seguintes;

4. Com isso, a Constituição de 1934, iniciou o processo de ascensão judicial brasileiro, na medida que inovou o controle de constitucionalidade existente e inseriu em nosso sistema jurídico o mandado de segurança e a ação popular. Pode-se dizer que, até aquele momento, a atuação do juiz estava restringida à (i)legalidade do ato praticado, a partir da inserção desses remédios jurídicos, conferiu-se ao magistrado a atuação na análise da conduta (política) do administrador público;

5. Com a ascensão de Vargas ao poder e a outorga da Carta de 1937, entretanto, o Judiciário assistiu a submissão de seus poderes ao Estado autoritário. O sistema de controle judicial das normas elaborado anteriormente foi rompido, em que pesasse ainda existir formalmente. A Constituição atribuiu ao Presidente poder para subverter as decisões do Tribunal que declarasse a invalidade da norma, acabando com qualquer controle judicial dos atos políticos praticados, concentrando os poderes do Estado na figura do ditador;

6. A redemocratização e a promulgação da Constituição de 1946, possibilitou ao Poder Judiciário retornar sua atuação do controle político por meio do judicial review, a Constituição retomou o sistema existente em 1934. Inovando-se em relação a Ação de Inconstitucionalidade Interventiva que seria proposta quando houvesse desrespeito a princípios sensíveis da Lei Fundamental;

7. Com o golpe de 64 e a concentração dos poderes políticos na ditadura, controvertidamente viu-se a ascensão dos mecanismos do controle constitucional das normas, de modo que se criou o controle abstrato das normas federais e estaduais, bem como 
regulamentou-se a ação popular, percebendo-se fatores que fundamentais para o crescimento da atividade judicial, ainda que não tenham sido preponderantes naquele período;

8. Por fim, concretizando o processo de ascensão judicial, a Constituição Federal de 1988 alargou o rol de legitimados para proposição de ação de controle de constitucionalidade, criou-se a Ação Declaratória de Constitucionalidade, o mandado de injunção e a sumula vinculante. Devido a esses fatores, resultou-se o surgimento dos fenômenos a judicialização da política e o ativismo judicial, tornando o judiciário um protagonista no processo político.

\section{CONSIDERAÇÕES FINAIS (ou Conclusão)}

O desenvolvimento do Estado Constitucional possui ampla correlação com a atuação dos três poderes. Nessa linha, o surgimento do constitucionalismo rompeu com a ordem absolutista no século XVIII, na qual imperava a figura do monarca, estabelecendo a atuação de poderes harmônicos e independentes que teriam suas funções delimitadas por uma Constituição, perdurando esse modelo clássico até o fim da primeira metade do século XX.

A partir desse período, com a remodelação dos países eixo derrotados na segunda guerra, reformulou-se o sistema jurídico com o surgimento o neoconstitucionalismo. Dotado de uma Constituição com força normativa e expansiva, amplamente expressa por normas de conteúdo aberto, buscou-se elaborar uma Lei Fundamental que afastasse os direitos fundamentais do cidadão de maiorias eventuais, ao passo que se elevou a figura do magistrado no papel interpretativo das normas, especialmente pela criação dos Tribunais Constitucionais.

Sendo que o mesmo cenário foi observado no Brasil. Com o surgimento do seu Estado em 1822, viu-se os poderes concentrados nas mãos do Império. Contudo, progressivamente, assistiu-se o desenvolvimento de um ideal constitucional que limitaria os poderes até sua efetiva concretização com a Constituição Federal de 1988. Nesse cenário, concomitantemente, ocorreu o crescimento da esfera judicial e da figura dos magistrados, desencadeando a ampla judicialização da política e o ativismo judicial visto na atualidade.

Ocorre que se demonstrou que esse processo não teve seu início com a Constituição Federal de 1988, como costumeiramente se infere. Pode-se afirmar que a ascensão da figura do magistrado remonta a década de 30 e a promulgação da Constituição de 1934 que inseriu no ordenamento jurídico pátrio remédios jurídicos que legitimaram o controle judicial da atividade política. Tendo isso se intensificado a cada nova Carta, como na vigência da Constituição de 1946 que se criou o controle abstrato de constitucionalidade ou na Lei Fundamental atual que ampliou os legitimados para proposição de ações de controle de constitucionalidade, entre outras ações inseridas no ordenamento jurídico.

Com efeito, conclui-se que o crescimento do Poder Judiciário brasileiro decorre de um longo período de desenvolvimento que se inicia na Constituição de 1934 e ganha novos contornos a cada período constitucional posterior. Não sendo, portanto, o cenário atual de grande proeminência judicial um fator exclusivo da Constituição Federal de 1988, não obstante sua profunda influência.

\section{REFERÊNCIAS}

ACKERMAN, Bruce. The Rise of World Constitutionalism. Faculty Scholarship Series. Paper 129. 1997. 
ASSIS, Luiz Gustavo Bambini de. Processo legislativo e orçamento público: a função de controle do parlamento. 2010. Tese (Doutorado em Direito do Estado) - Faculdade de Direito, Universidade de São Paulo, São Paulo, 2010.

BARROSO, Luís Roberto. Curso de Direito Constitucional Contemporâneo. Editora Saraiva. São Paulo. 2014.

Neoconstitucionalismo e constitucionalização do Direito (O triunfo tardio do direito constitucional no Brasil). Revista de Direito Administrativo, Rio de Janeiro. 2005.

; BARCELLOS, Ana Paula de. O começo da história. A nova interpretação constitucional e o papel dos princípios no direito brasileiro. Revista de Direito Administrativo, Rio de Janeiro. 2003.

BONAVIDES, Paulo; ANDRADE, Paes de. História Constitucional do Brasil. Editora Paz e Terra S/A. São Paulo. 1991.

CAPPELLETTI, Mauro. Juízes Legisladores?. Sergio Antonio Fabris Editor. Porto Alegre. 1993.

FERREIRA FILHO, Manoel Gonçalves. Poder Judiciário na Constituição de 1988: judicialização da política e politização da justiça. Revista de Direito Administrativo, Rio de Janeiro, 1994.

GALVÃO, Jorge Octávio Lavocat. O neoconstitucionalismo e o fim do estado de direito. 2012. Tese (Doutorado em Direito do Estado) - Faculdade de Direito, Universidade de São Paulo, São Paulo, 2012.

HIRSCHL, Ran. Towards Juristocracy - The origins and consequences of the new constitutionalism. Harvard University Press. Cambridge. 2007.

LOEWENSTEIN, Karl. Teoría de la Constitución. Editora Ariel. Barcelona. 1979.

LUHMANN, Niklas. A Constituição como aquisição evolutiva. In: ZAGREBELSKY, Gustavo. PORTINARO, Pier Paolo. LUTHER, Jorg. Il futuro della costituzione. Torino: Einaudi, 1996. Tradução: Menelick de Carvalho Netto.

NEVES, Lucia Maria Bastos Pereira das. Constituição: usos antigos e novos de um conceito no Império do Brasil (1821-1860). In: CARVALHO, José Murilo de; NEVES, Lucia Maria Bastos das (Org.). Repensando o Brasil do Oitocentos: cidadania, política e liberdade. Rio de Janeiro: Civilização Brasileira, 2009.

RAMOS, Elival da Silva. Ativismo Judicial - Parâmetros dogmáticos. Editora Saraiva. São Paulo. 2015.

SARLET, Ingo Wolfgang; MARINONI, Luiz Guilherme; MITIDIERO, Daniel. Curso de Direito Constitucional. Saraiva. São Paulo. 2015.

SARMENTO, Daniel. O neoconstitucionalismo no Brasil: riscos e possibilidades. Revista Brasileira de Estudos Constitucionais. Belo Horizonte. 2009.

SILVA, José Afonso da. Curso de Direito Constitucional Positivo. Editora Malheiros. São Paulo. 2014.

STRECK, Lenio Luiz. Jurisdição Constitucional e Hermenêutica. Uma nova crítica do Direito. Livraria do Advogado. Porto Alegre. 2002.

TUSHNET, Mark. Taking the Constitution Away from the Courts. Princeton University Press. Princeton. 1999.

VICTOR, Sérgio Antônio Ferreira. Diálogo Institucional e Controle de Constitucionalidade: Debate entre o STF e o Congresso Nacional. Saraiva. São Paulo. 2015. 